\title{
Research on Value Assessment of Agricultural Land Transfer Right in the Process of New-type Urbanization
}

\author{
Fangxin Di \\ Hetao College, Bayannaoer, 015000, China
}

Keywords: Agricultural land, Right of transfer, Value assessment

\begin{abstract}
On the premise of optimization of resource allocation, formation of agricultural scale and guarantee of farmers' interests, the theory and method of assets appraisal is used in this paper to research value assessment of agricultural land transfer right in the process of new-type urbanization from the following perspectives: significance and inevitability of agricultural land transfer, necessity of value assessment for agricultural land transfer right, value assessment method of agricultural land transfer right, and effective means used for completion of value assessment of agricultural land transfer right.
\end{abstract}

\section{Introduction}

Continuous increase in investment into rural economic construction and quickening construction pace of new-type urbanization resulted in rapid development of economic marketization in rural areas. Among basic elements of agricultural production, agricultural land is served as the guarantee for survival of most farmers. Under current circumstances, operation mode of agricultural land is mainly of small scale, decentralized operation and appropriate-scale intensive management. Contradictions between the two operation modes become obvious day by day. They cannot adapt to the requirements of large-scale agricultural production and modern agriculture. However, transfer of agricultural land contracted management right is an effective measure to solve these contradictions.

Quickening construction pace of new-type urbanization, transfer of surplus rural labor force and decrease in leftover population make it inevitable for transfer of agricultural land

In economic development in rural areas, priority among priorities is to quicken the construction pace of new-type urbanization ${ }^{\mathbf{I} 1}$. At present, China is in the critical period of balancing urban and rural development, quickening transformation of traditional agriculture and constructing modern agriculture. Implementation of benefit farming policy, remission of agricultural tax, improvement to agricultural land value, transfer of leftover population and improvement to farmers' employment opportunity and employment environment in cities will inevitably lead to transfer of agricultural land [21. Transfer right of agricultural land is an important property right for farmers. It is allowed for free transfer of agricultural land, making farmers trustingly work and settle in cities. Industrialized operation is realized for agriculture. Land revenues are higher than those under decentralized operation. Therefore, employment vision of surplus labor will be transferred to cities and developed toward secondary and tertiary industries, laying a foundation for construction of new-type urbanization.

Transfer of agricultural land is helpful for land, fund and technology integration as well as formation of agricultural scale.

Unreasonable rural industrial structure makes it difficult for Chinese agriculture to realize scale merit. Contradictions are generated between single-family management structure and specialized production under household responsibility system and between small-scale scattered land management structure and intensive production of modern agriculture. Lands can be concentrated for overall arrangement only through transfer of agricultural land management right, so as to give full play to advantages of fund, technology and management. Land contractors and operators introduced advanced funds and modern protection technologies \& equipment to solve the problem of employment of local farmers, making land transferred from idle state into use state, realizing optimal 
configuration between land resources and fund, technology, labor and other resources, and improving land service efficiency. Agricultural structure adjustment plays a role in promoting economic development in rural areas. Rural industrial structure adjustment can be promoted, and rural economic development can be quickened only by establishing flexible and high-efficiency land transfer mechanism and gradually concentrate lands for scale operation.

Based on explicit use right, disposal right and compensation authority for farmers for lands under contracted management, therefore, it is of great importance to allow farmers to have the right of management and transfer for contracted lands.

\section{Necessity for Value Assessment for Agricultural Land Transfer Right in the Process of New-type Urbanization}

Value assessment for agricultural land transfer right is quite different from traditional land value assessment. Usually, the object in traditional land valuation is developed land in cities. It is more mature for urban developed land transaction market, and it is easier for determination of estimated value. Professional land appraisal agencies and evaluators are involved in this process of land appraisal. For value assessment of agricultural land transfer right, however, this business started relatively late. Therefore, its market growth is relatively laggard, and seriously restrained. Therefore, the government should encourage and support establishment of the third-party assessment intermediaries with relevant qualifications to provide value assessment services to agricultural land transfer right, promote the transfer of agricultural land with fair and reasonable prices, and complete rural industrial structure adjustment. ${ }^{[3]}$

\section{Analysis on Value Assessment Method of Agricultural Land Transfer Right in the Process of New-type Urbanization}

At present, some scholars have already realized that the value of agricultural land transfer right is a key factor breaking the problem of land transfer. Moreover, they also discussed the selection of methods used for value assessment of agricultural land transfer right. ${ }^{[4]}$

\section{Diversity of assessment methods}

In the latest Regulations for Agricultural Land Appraisal (GB/T 28406-2012), there are 6 methods for agricultural land appraisal, i.e. income approach, cost approach method, residual method, score appraisal method, market comparison approach and benchmark land price correction method. According to existing researches, land management right with family as a unit has special features. Although above methods are feasible, they are incompletely applicable. Therefore, the selection of assessment methods is under certain limitations. Firstly, the basic premise of cost approach method is that assets to be evaluated are in the state of continuous use and must be regenerative or replicable. Secondly, residual method is a method in which estimated normal development costs and relevant professional fees, interests and taxes are deducted based on normal transaction value of agricultural land after the completion of estimated development, and the price balance is used to estimate the value of agricultural land to be estimated. Residual method is applicable to price evaluation of agricultural land to be developed. It is somewhat similar to cost approach method. Both methods estimate the value of agricultural land transfer right from the angles of agricultural land development costs and appreciation of estimated transaction value. However, the precondition is that agricultural land is transacted according to relevant laws. Thus, current investment can be smoothly realized and obtain adaptive expectations in the future by means of transaction. Therefore, application of residual method is limited in the range of use. Thirdly, score appraisal method is a valuation method in which the system of factors influencing agricultural land price and factor marking criteria are established according to certain principles, relevant conditions of agricultural land to be assessed are scored according to the marking criteria, and cores are multiplied by objective unit score price of agricultural land according to relevant scores, so as to obtain the price of agricultural land. Fourthly, basic premise of market comparison approach is to have an active public market. In this market, there 
should be enough comparable information or trading activities. Fifthly, benchmark land price method is a method in which the table of benchmark land price and benchmark land price correction factor is taken as the basis for valuation, regional conditions and individual conditions of regions to be estimated are diagnosed according to substitution principles, relevant correction factors are selected for correction according to the table of benchmark land price correction factor, so as to obtain the value of agricultural land to be estimated. Sixthly, income approach is a method in which future prospective earnings of agricultural land to be estimated are converted into prevent value, so as to determine the value of the land. Actually, it is about quantization and present valuation of profitability of agricultural land transfer value.

\section{Proper application of income approach in value assessment for agricultural land transfer right}

When income approach is properly applied in value assessment for agricultural land transfer right, evaluators must strictly master the following aspects:

Strictly master the use of income approach

In Regulations for Agricultural Land Appraisal, income approach is mainly involved in annual net income and land reduction rate. Firstly, get annual net income; annual net income of land is the difference between total annual income and total annual cost. Secondly, determine land reduction rate; three methods for determination of land reduction rate are proposed in Regulations for Agricultural Land Appraisal: rent comparison method, secure interest rate plus risk adjustment value method and comprehensive ranking interpolation method of investment risk \& investment return rate.

Strictly control data collection, and accurately calculate various indexes

Application of income approach requires enough data as the basis. For instance, annual net return of land is the difference between total annual income and total annual cost. While determining total annual income, production and management mode of agricultural land is a key element. Different production and management modes of agricultural land to be estimated may result in different total annual incomes. For instance, annual incomes of agricultural products are taken as total annual income, if the production and management mode is of direct type. If the production and management mode is of leasing type, total annual income is the sum of annual rentals and interest incomes of cash deposit or cash pledge. Production and management mode of agricultural land is also a key factor while determining total annual costs. If the production and management mode of agricultural land to be estimated is of direct type, total costs refer to the sum of maintenance charges and costs for production of subsidiary agricultural products. If the production and management mode is of leasing type, total costs should be determined according to annual average expenses in the leasing process. For land reduction rate, the three methods have respective advantages. It is difficult for selection. In the practice of valuation, the most proper method can be used for determination according to market conditions of local agricultural land.

\section{Effective Approaches Used to Guarantee Proper Application of Agricultural Land Transfer Right Value Assessment Method}

\section{Establish professional intermediary appraisal agencies and arbitral institutions}

We should quicken the pace of establishing intermediary organs and arbitral institutions for transfer of agricultural land. Intermediary organs are responsible for executing pricing and consultation services of agricultural land transfer right, and agricultural land transfer right dispute arbitral institutions for handling disputes in the transfer process of agricultural land.

1). Establish intermediary organs for value assessment of agricultural land transfer right: assets appraisal is of high profession and technology. It is very difficult for farmers to estimate the values of their land transfer rights. To avoid deviation of agricultural land transfer right value from market value rules, we should gradually establish professional intermediaries for value assessment of agricultural land transfer right, complete its functions, guide its legal and integrity services, improve farmers' initiative for land transfer, maintain farmers' legal interests, and objectively evaluate by standing in the angle of a third party. While establishing land transfer right value assessment 
intermediaries, we should also take the issue of costs into full consideration. Moreover, farmers' economic conditions also make them unwilling to pay assessment expenses. Therefore, relevant governmental departments can act this responsibility on behalf of farmers in the initial stage. After mature development, such responsibility should be canceled and delivered to the market.

2). Establish arbitral institutions for solving agricultural land transfer disputes: at present, defects of land transfer organizations lead farmers to have unclear understanding of relevant agricultural land transfer right systems in China. In the transfer process, some farmers didn't follow certain procedures or perform necessary procedures. Bilateral rights and obligations were not restrained by signing a transfer contract between both parties, or an oral agreement is excluded from legal protection, causing numerous disputes and affecting social stability. Arbitral institutions should be local courts. However, economic experts should be arbitrators. For other disputes out of transfer right value, legal experts can arbitrate according to relevant laws. However, transfer right value disputes can be clearer only through judgment by economic experts.

3). Establish other intermediaries serving transfer of agricultural land under the guidance of the government: main function of agricultural land transfer intermediaries is to guide farmers' transfer right transactions into the market for circulation and exchange and to provide transfer services to these farmers. Besides transfer right value assessment institutions, transfer management organizations, intermediary service institutions and notarization service institutions are also included. It is of particular importance for management organizations, which are responsible for organizing implementation of agricultural land transfer, for information collection, processing, releasing and transfer consultation, for guiding others to sign transfer contract and transact transfer procedures, for providing sites for negotiation and transaction of agricultural land transfer, and for further realizing security for a loan, management right shareholding and transfer right securitization platform. Intermediary service institutions should give full play to their functions in service guidance, master transfer information of rural land by virtue of high-tech information technology, provide symmetrical information for both parties of transfer, and make land transfer step into the goals of marketization, informatization and standardization.

We should realize scale operation of land, gradually increase the quantity of land into the market, vigorously develop agricultural land intermediary organs, and enhance service of these organs, so as to provide strong guarantees for completion of value assessment for agricultural land transfer right.

Quicken promotion of assets assessment legislation, standardize appraisal agencies, and complete professional norms for evaluators

Assets appraisal is a complex, dynamic and market-oriented process. Assessment result is affected by evaluation subject. Therefore, assets appraisal is of certain subjective assumption. Impartial, objective, scientific and reasonable assessment guarantees both parties' rights and obligations, and avoids the occurrence of unfair transaction. Therefore, we should quicken the promotion of assets appraisal legislation, fill up vacancies of legal systems, and create a favorable industrial environment for the third-party intermediaries. Moreover, we should also standardize appraisal agencies, promote healthy development of assessment industry, and never overlook the leading role of the government. The government should enhance supervision and administration toward the third-party appraisal agencies, delegate powers to lower levels, give play to the function of property valuation association, and jointly establish an agricultural land transfer right value assessment system suitable for our national conditions. Professional norm is an important basis for effective implementation of self-regulation, organization and management and for standardization of land evaluators' professional ethics. Fair, scientific, objective and reasonable assessment result requires professional land evaluators to strictly follow relevant national laws and regulations in the evaluation process, to assess the value of agricultural land according to relevant legal criteria and procedures, and to correctly and rationally give play to their roles.

Comprehensively realize shareholding of agricultural land management right and develop industrialization of agriculture

In the transfer process of agricultural land, what is transferred is not ownership. Agricultural land is owned by collective instead of single farmer. Therefore, what is transferred is management right. 
Therefore, development of agricultural industrialization with shareholding of agricultural land management right is of great significance for enriching and completing the functions of land contractual right, deepening integration of various participators in the agricultural industry chains and optimizing various production elements. Real estate properties are of poor liquidity. However, the essence of shareholding is to transact cash flow formed from earnings obtained from real estate properties in the future and to make such cash flow become financial assets with strong liquidity.

\section{Acknowledgments}

This paper is the planned project of Inner Mongolia social sciences in 2014 (name: Research on the Issue of Land Transfer in the Process of New-type Urbanization; No.: 2014B029).

\section{References}

[1] Wang Yinping, Significance and Pattern of Transfer of Rural Land Use Rights, Modern Agriculture, 2010, (15);

[2] Zhang Min, Analysis on Legal Issues of Transfer of Rural Land Contractual Management Right, Agricultural Economy, 2011, (10);

[3] Wang Bin and others, Research on Transfer Value Assessment of Rural Land Contractual Management Right, Price: Theory \& Practice, 2009, (11);

[4] Yu Kaifeng, Research on Transfer Value Assessment of Rural Land Permanent Contracted Management Right, Xinjiang State Farms Economy, 2012, (10) 